\title{
Geociênchciass
}

\section{Litofácies sedimentares da Formação Sopa-Brumadinho no Campo Diamantífero de Extração (Diamantina, MG)}

\section{Sedimentary lithofacies of the Sopa-Brumadinho Formation at the Extraction Diamond Field (Diamantina, Minas Gerais)}

Marcio Célio Rodrigues da Silva

Geomil Serviços de Mineração Ltda.

Mestre em Geologia pelo IGC/UFMG.

Belo Horizonte-MG.

celio@geomil.com.br

Mario Luiz de Sá C. Chaves

Professor do CPMTC-IGC/UFMG.

Pesquisador CNPq, Belo Horizonte-MG.

mchaves@ufmg.br

\section{Resumo}

Levantamento geológico de detalhe, realizado na Formação Sopa-Brumadinho (Supergrupo Espinhaço), na área do Campo Diamantífero de Extração (Diamantina, MG), identificou o registro de um conjunto de depósitos sedimentares de características essencialmente continentais. Tais depósitos representam a transição de um regime de quiescência tectônica, em sistema fluvial entrelaçado, para outro controlado tectonicamente por falhamentos da fase rifte da bacia, com a formação de depósitos fluviais incisos e de leques aluviais. A análise faciológica, com suporte na identificação dos elementos arquiteturais dessa formação, permitiu o estabelecimento de sete associações de litofácies (A1 a A7), que caracterizam a evolução dos sistemas deposicionais do Supergrupo Espinhaço, nesse sítio. As ocorrências de diamantes conhecidas nas antigas minas relacionam-se, sobretudo, à Associação A2 e, provavelmente, também, à Associação A3.

Palavras-chave: Litofácies sedimentares, Formação Sopa-Brumadinho, Diamantina (MG).

\begin{abstract}
Detailed geological mapping of the Sopa-Brumadinho Formation (Espinhaço Supergroup) in the area of the Extração Diamondiferous Field (Diamantina, MG), identified a series of sedimentary continental deposits. These deposits indicate the transition from a quiescent tectonic regime with braided rivers to another regime controlled by rift-related faults in the basin, with the development of incised fluvial deposits and alluvial fans. By the facies analysis supported in the identification of architectural elements of this formation, were recognized seven lithofacies associations (A1 to A7) that characterize the evolution of the depositional systems of Espinhaço Supergroup in the area. Diamond occurrences that are known in the old local mines can be related to A2 Association and, probably, also to A3 Association.
\end{abstract}

Keywords: Sedimentary lithofacies, Sopa-Brumadinho Formation, Diamantina town (MG). 


\section{Introdução}

A região de Diamantina, centronorte de Minas Gerais, destacou-se, no passado, como uma das mais clássicas produtoras de diamantes do país. As principais atividades mineradoras se desenvolveram em depósitos aluvionares quaternários, embora parcela significativa do trabalho de extração tenha também enfocado os conglomerados proterozoicos da Formação Sopa-Brumadinho (Supergrupo Espinhaço). Entre as principais áreas, onde essas rochas es- tão expostas, destaca-se o Campo Diamantífero de Extração (Chaves, 1997), localizado cerca de $10 \mathrm{~km}$ a leste de Diamantina (Figura 1).

$\mathrm{O}$ interesse pelo estudo dessa área decorre do fato de que rochas conglomeráticas da Formação Sopa-Brumadinho constituem ainda importantes reservas de material diamantífero, encontradas em volumes significativos nas antigas jazidas Boa Vista, Cafundó, Cavalo Morto e Serrinha. Mapeamento geológico foi

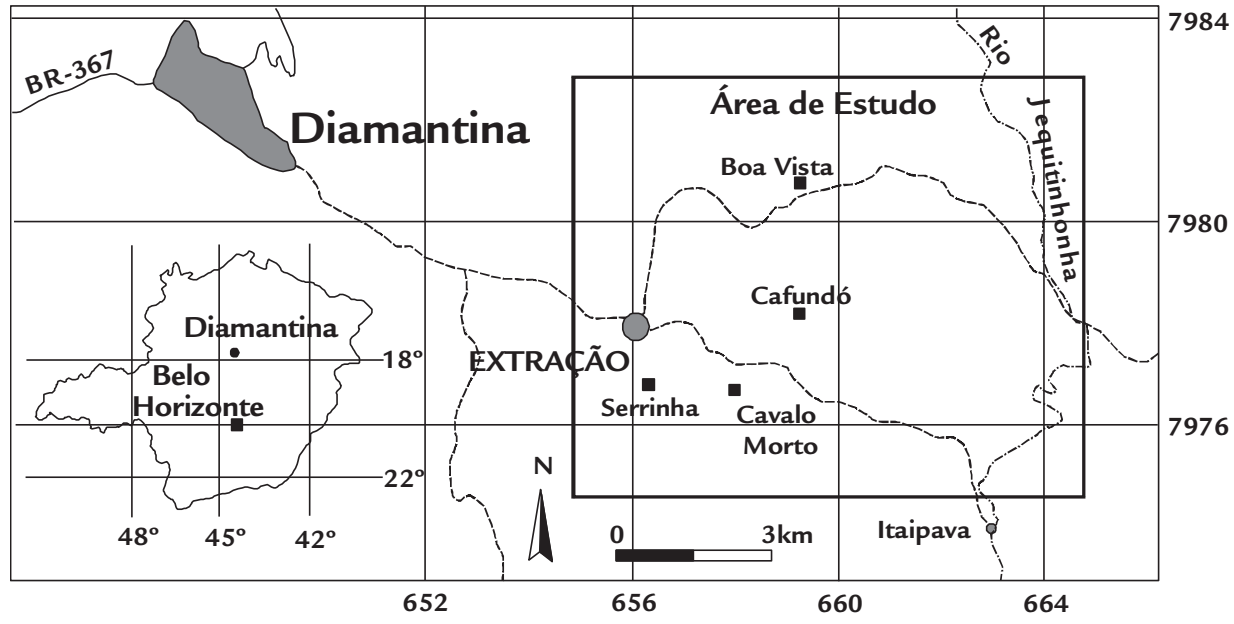

\section{Contexto geológico}

A região de Extração insere-se na porção mediana central da Serra do Espinhaço Meridional, onde aflora a porção inferior do Supergrupo Espinhaço, enfeixada no Grupo Diamantina (Dossin et al., 1990), que é representado por formações siliciclásticas, intrudidas na porção basal por rochas metamagmáticas conhecidas como "filitos hematíticos". Essas sequências foram deformadas durante o Ciclo Orogênico Brasiliano (650-500 Ma), sob metamorfismo de fácies xisto verde baixo, o que preservou a maioria das estruturas sedimentares originais, embora, localmente, tenham se desenvolvido foliações conspícuas em suas rochas. Essas foliações podem ser descritas como uma xistosidade ou clivagem, de caráter plano-axial, nas zonas de baixa magnitude de deformação, ou se apresentar como uma foliação milonítica, em estreitas zonas de cisalhamento com feições anastomosadas. Em áreas mais deformadas, desenvolveram-se rampas e patamares associados a falhas de cavalgamento, configurando estruturas desenvolvidas em regime rúptil a dúctilrúptil (Rosière et al., 1994).

O Grupo Diamantina distribui-se na região serrana em faixas de direção N-S, conformando anticlinais e sinclinais curtos, assimétricos e, muita vezes, falhados, com imbricamentos vergentes para oeste. As maiores espessuras e a sequência completa dessa unidade ocorrem nas proximidades de Diamantina (Dossin et al., 1990). Na base, ocorrem conglomerados e quartzitos grossos, sobrepostos por quartzitos finos a médios, realizado apenas em escala 1:100.000, no âmbito do Projeto Espinhaço (Fogaça, 1996), além dos estudos desenvolvidos por Alvarenga (1982), Almeida Abreu \& Munhoz (1983) e Haralyi \& Svisero (1986), que não aprofundaram no reconhecimento das variações faciológicas ou na distinção dos sistemas deposicionais presentes. Esses enfoques, com base em levantamento geológico de detalhe (1:10.000), representam o objetivo do atual trabalho.
Figura 1

Localização e acesso à área de Extração, a leste de Diamantina (MG), destacando as principais lavras diamantíferas. ricos em estruturas sedimentares, que indicam deposição continental (Formação São João da Chapada). Acima, em discordância erosiva, aflora uma sucessão de filitos e quartzitos finos a grossos, com intercalações de conglomerados polimíticos, diamantíferos, essencialmente continentais, estudados em detalhe na região em foco (Formação Sopa-Brumadinho). No topo, esses depósitos são cobertos, em nova discordância erosiva, por quartzitos finos de elevado grau de pureza, com estratificações cruzadas de grande porte, que representam sedimentação em ambiente eólico (Formação Galho do Miguel). Este conjunto registra a sedimentação da fase rifte, intracratônica, da bacia Espinhaço (Dossin \& Dossin, 1995; Martins-Neto, 1998).

\section{Litofácies sedimentares na formação Sopa-Brumadinho}

No presente trabalho, foram reconhecidas sete associações de litofácies nessa formação, cuja distribuição pode ser observada no mapa litofaciológico (Figura 2).
Em vista do excelente estado de preservação das rochas e estruturas sedimentares presentes, devido ao caráter localizado das deformações tectônicas, que, nesse campo diamantífero, estão concentradas em estreitas faixas de cisalhamento dúctil-rúptil subverticalizadas, na descrição das litofácies, não se utilizarão as nomenclaturas metamórficas pertinentes. 
Figura 2 Mapa litofaciológico da Formação SopaBrumadinho no Campo Diamantífero de Extração (Escala original 1:10.000).

\section{Associação de Litofácies A1}

Exposta principalmente no entorno do campo diamantífero, apresenta ampla predominância de arenitos, com conglomerados intercalados, ambos por vezes ferruginosos. Os arenitos são médios a grossos, localmente microconglomeráticos ou com seixos centimétricos esparsos de quartzo. São comuns estratificações plano-paralelas e cruzadas tabulares de pequeno porte ou acanaladas de porte métrico. Os conglomerados podem ser suportados pela matriz ou pelos clastos. Quando suportados pela matriz, esta é

\section{Associação de Litofácies A2}

Está presente nas antigas minas Boa Vista, Cavalo Morto e Serrinha, onde foi extensamente lavrada e quase exaurida. Constitui-se de conglomerados suportados por clastos, de arcabouço pouco organizado a desorganizado, destacando um tipo maciço e bem selecionado, com blocos/matacões $(10-50 \mathrm{~cm})$ subarredondados, em geral de quartzitos. Sua matriz é pelítica a psamopelítica esverdea$\mathrm{da}$, de caráter grauvaquiano e arcoseano

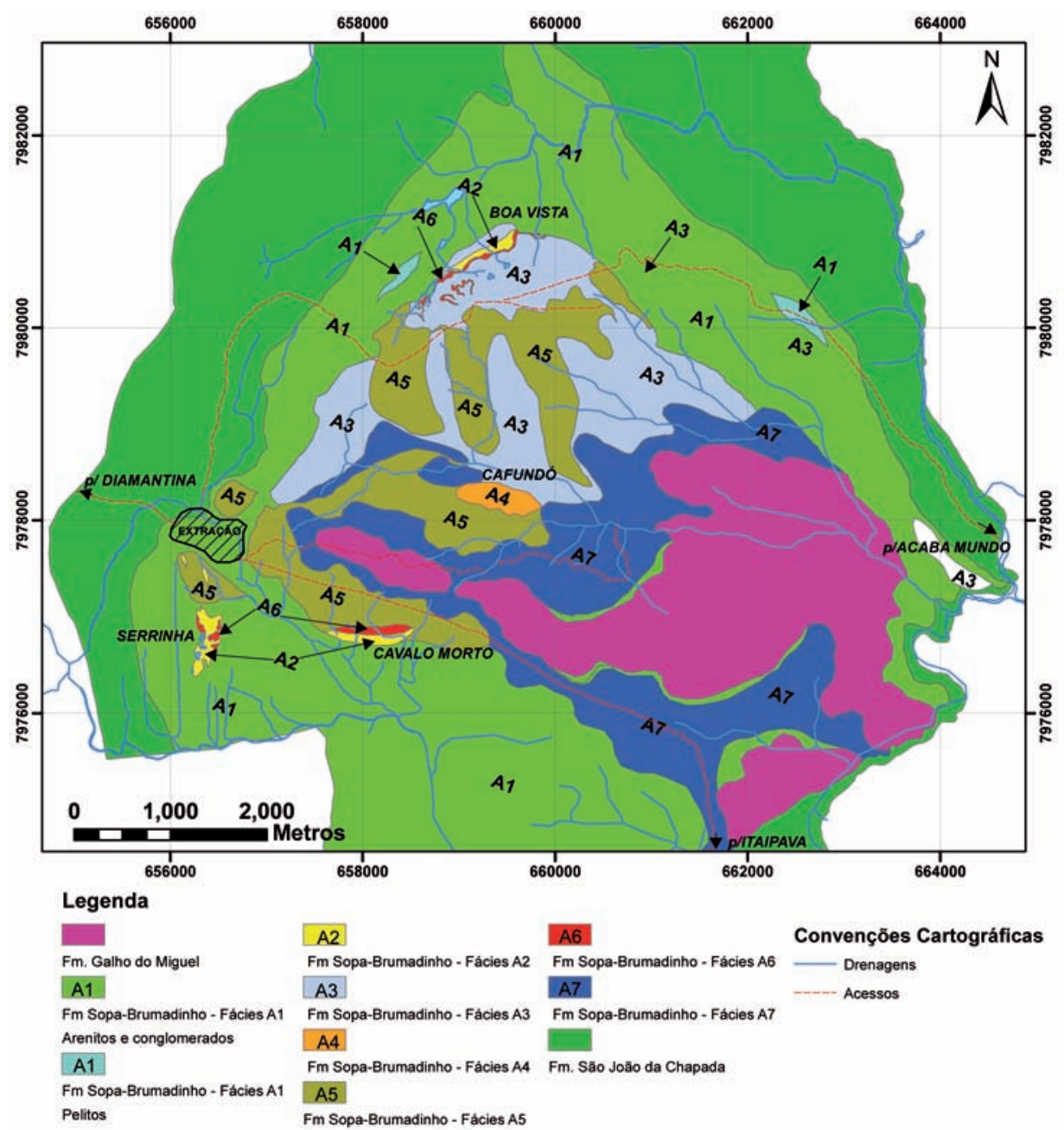

arenosa, com seixos de quartzo leitoso subarredondados $(<10 \mathrm{~cm})$, em corpos não gradados, lenticulares, de espessura submétrica. Localmente, mostram elevado conteúdo de clastos e caráter clastosuportado, podendo exibir gradação inversa (Prancha 1A). Distingue-se, ainda, outro tipo de conglomerado, caracterizado pelo conteúdo ferruginoso da matriz, ora suportado pela matriz arenosa, com clastos esparsos de quartzo e quartzito, centimétricos e subangulosos $(<10 \mathrm{~cm})$, ora suportados por clastos de quartzitos

(Prancha 1B), estando tipicamente representada na Lavra Serrinha. Inclui, ainda, conglomerados inversamente gradados, com blocos e matacões subarredondados de quartzito $(10-50 \mathrm{~cm})$, em matriz areno-conglomerática à base de seixos centimétricos $(2-5 \mathrm{~cm})$ de quartzo dispersos, associados à uma arquitetura em canal na base, bem descritos na Lavra Boa Vista. Ocorre localmente um conglomerado suportado pela matriz, não angulosos a subarredondados $(5-20 \mathrm{~cm})$, com baixo grau de selecionamento, em matriz arenosa grossa, ambos como lentes de espessura métrica em arenitos. Entre as rochas pelíticas, predominam siltitos esverdeados, com marcas onduladas centimétricas.

Interpretou-se essa associação como originada em sistema fluvial entrelaçado (Miall, 1978), o qual marca a fase inicial de sedimentação da Formação Sopa-Brumadinho na área, em período de atividade tectônica pouco expressiva.

gradado, com blocos/matacões de quartzitos subarredondados a subangulosos $(10-50 \mathrm{~cm})$, muitos imbricados, em matriz com seixos de quartzo centimétricos $(2-6 \mathrm{~cm})$, subarredondados, imersos em sedimentos arenosos (Prancha $1 \mathrm{C}-\mathrm{Boa}$ Vista). Litofácies psamíticas constituem lentes estreitas de arenitos $(<50 \mathrm{~cm})$, horizontais ou com laminações cruzadas de baixo ângulo, associadas aos conglomerados de clastos imbricados, e arenitos 
com granulometria média e estratificação horizontalizada, em bancos espessos (2-5m) no topo dos conglomerados (Serrinha).

\section{Associação de Litofácies A3}

Entre a Mina Boa Vista e o Córrego Cafundó (parte central da área), expõe-se uma associação essencialmente conglomerática com arenitos subordinados, ambos de matriz arcoseana e/ou grauvaquiana. Os conglomerados possuem arcabouço com clastos bem organizados, compreendendo fácies suportadas por clastos ou pela matriz, com frequentes bancos areníticos intercalados. Os mais representativos e provavelmente proximais são suportados por clastos de quartzitos (formação ferrífera e fuchsita quartzito subordinada), subangulosos a subarredondados, não gradados e de matriz arenosa média (Prancha 1D).

\section{Associação de Litofácies A4}

De ocorrência típica na Mina Cafundó, exibe caráter essencialmente psefítico, com reduzidas variações fáciológicas e estrutura desorganizada. Compõe-se por conglomerados suportados pelos clastos, desde seixos de quartzo $(1-3 \mathrm{~cm})$ a matacões de quartzito branco $(0,6-1,2 \mathrm{~m})$, extremamente

\section{Associação de Litofácies A5}

Com ampla distribuição na área, é representada por depósitos conglomeráticos com intercalações areníticas frequentes, cuja principal característica é a estrutura acamadada. Destaca-se um conglomerado com estratificação planar, suportado por clastos de quartzo de veio (arredondados a subarredondados), além de quartzito ferruginoso e de formação ferrífera $(3-10 \mathrm{~cm})$ em matriz arenosa

\section{Associação de Litofácies A6}

Caracterizada nas antigas minas Serrinha, Cavalo Morto e Boa Vista, onde ocorrem recobrindo os litofácies de A2 e A3. Trata-se de uma associação conglomerática, na qual se reconhecem conglomerados suportados por clastos,
Esses depósitos resultaram de um sistema deposicional fluvial inciso, decorrente da intensificação dos processos distensivos de formação da bacia, que

Nestes, predominam seixos $(5-15 \mathrm{~cm})$, além de blocos arredondados de quartzito $(<20 \mathrm{~cm})$. Como variação faciológica local, ocorre um conglomerado com seixos de quartzo predominantes $(3-8 \mathrm{~cm})$, arredondados a subarredondados em matriz arenítica, contendo matacões angulosos esparsos de quartzito $(35-70 \mathrm{~cm})$, nos quais o conglomerado fino constitui a matriz na qual estão imersos os matacões. Em porções possivelmente mais distais, ocorrem conglomerados suportados pela matriz arenosa (também arcoseana e/ou grauvaquiana), não gradados, com clastos subarredondados de natureza semelhante aos primeiros, variando de sei-

mal selecionados e às vezes verticalizados (Prancha 1E). A matriz varia de conglomerática a arenosa. Em quantidades menores, ocorrem seixos a matacões de quartzitoferruginoso, formação ferrífera, conglomerado e rocha metaígnea. Nos matacões quartzíticos, alguns de coloração vermelha acentuada, são

(Prancha 1F). Localmente, ocorre litofácies conglomerática de estrutura maciça e clastos em duas modas granulométricas; uma mais fina $(6-12 \mathrm{~cm})$ e outra mais grossa $(20-40 \mathrm{~cm})$, sendo a grande maioria de quartzo e quartzito branco (quartzito ferruginoso e formação ferrífera raros). Litofácies psamíticas correspondem a arenitos médios a grossos, com estratificação planar de mergulhos

maciços e desorganizados, com seixos e blocos angulosos de quartzitos em típica matriz areno-siltosa a siltosa (Prancha $1 \mathrm{G})$, e conglomerados de igual matriz, suportados por clastos, melhor organizados, com seixos e blocos arredondados provocaram a descida do nível de base e erosão dos canais entrelaçados pretéritos (Miall, 1996; Eriksson et al., 2005). xos a blocos $(5-10 \mathrm{~cm})$ e localmente com matacões subarredondados de quartzito $(30-35 \mathrm{~cm})$. Termos psamíticos incluem arenitos maciços, em bancos centimétricos $(30-50 \mathrm{~cm})$, e arenitos de granulometria média com estratificação planar, exibindo seixos esparsos, em camadas métricas (1-2m).

Essa associação foi interpretada como o registro de um sistema de leque aluvial dominado por fluxos aquosos e de corrente (Bull, 1977; Galloway \& Hobday, 1996), em seus domínios proximais a medianos, tendo, provavelmente, as mesmas fontes dos depósitos da Associação A2. frequentes as estratificações cruzadas de pequeno porte.

O comportamento brechoide e o arcabouço caótico corroboram a interpretação de que esta associação possivelmente resulte de um sistema de leque aluvial dominado por processos de avalanches (Blair \& Mcpherson, 1994). suaves, em lentes de espessura métrica ou submétrica.

Essa associação foi, provavelmente, desenvolvida em sistema deposicional de leque aluvial dominado por escoamento em lençol (Blair \& Mcpherson, 1994; Galloway \& Hobday, 1996), pela sedimentação resultante da atuação de fluxos aquosos não canalizados, com elevada carga de sedimentos.

\section{Associação de Litofácies A7}

Ocorre no setor sudeste do campo, de modo característico na estrada para o vilarejo de Itaipava. Constituise, essencialmente, por arenitos médios de quartzo e quartzito, apresentando moderada estratificação plano-paralela.

Tal associação foi interpretada como o registro de um sistema de leque aluvial dominado por fluxos de detritos (Galloway \& Hobday, 1996). a finos, com siltitos subordinados e conglomerados raríssimos. Os arenitos 
Prancha 1

A: Arenito médio a grosso, com grânulos ferruginosos nos planos de estratificação cruzada tabular (Associação A1); B: Conglomerado suportado por clastos, não gradado, a calhaus e matacões de quartzito, subarredondados, em matriz psamo-pelítica (Serrinha, Associação A2); C: Conglomerado suportado pela matriz conglomerática, não gradado, com blocos e matacões imbricados de quartzito, com lente arenosa portando laminação cruzada de baixo ângulo, assentados sobre conglomerado de matriz

arenosa suportado por clastos (Boa Vista, Associação A2); D: Conglomerado suportado pelos clastos, não gradado,

a seixos de quartzo e quartzito predominantes, subarredondados em matriz arenosa, mostrando lente arenosa com laminação cruzada de baixo ângulo (Associação A3); E: Conglomerado suportado por clastos, não gradado, a matacões de portes variáveis, incluindo alguns em posição verticalizada (Associação A4); F: Conglomerado suportado por clastos, a seixos de quartzo em matriz arenosa, não gradados, com estratificação horizontal

(Lavra Nove Vinténs, Associação A5);

G: Conglomerado suportado por seixos e blocos angulosos, imersos de forma desorganizada na matriz areno-pelítica (Associação A6); H: Arenito siltoso com estratificação horizontalizada incipiente (Estrada para Itaipava, Associação A7).

são imaturos, arcoseanos e/ou grauvaquianos, com estratificação horizontalizada e, de modo geral, incipiente, com cores cinza ou branca amarelada (Prancha 1H). Os siltitos são acinzentados, com estratificação plano-parale-
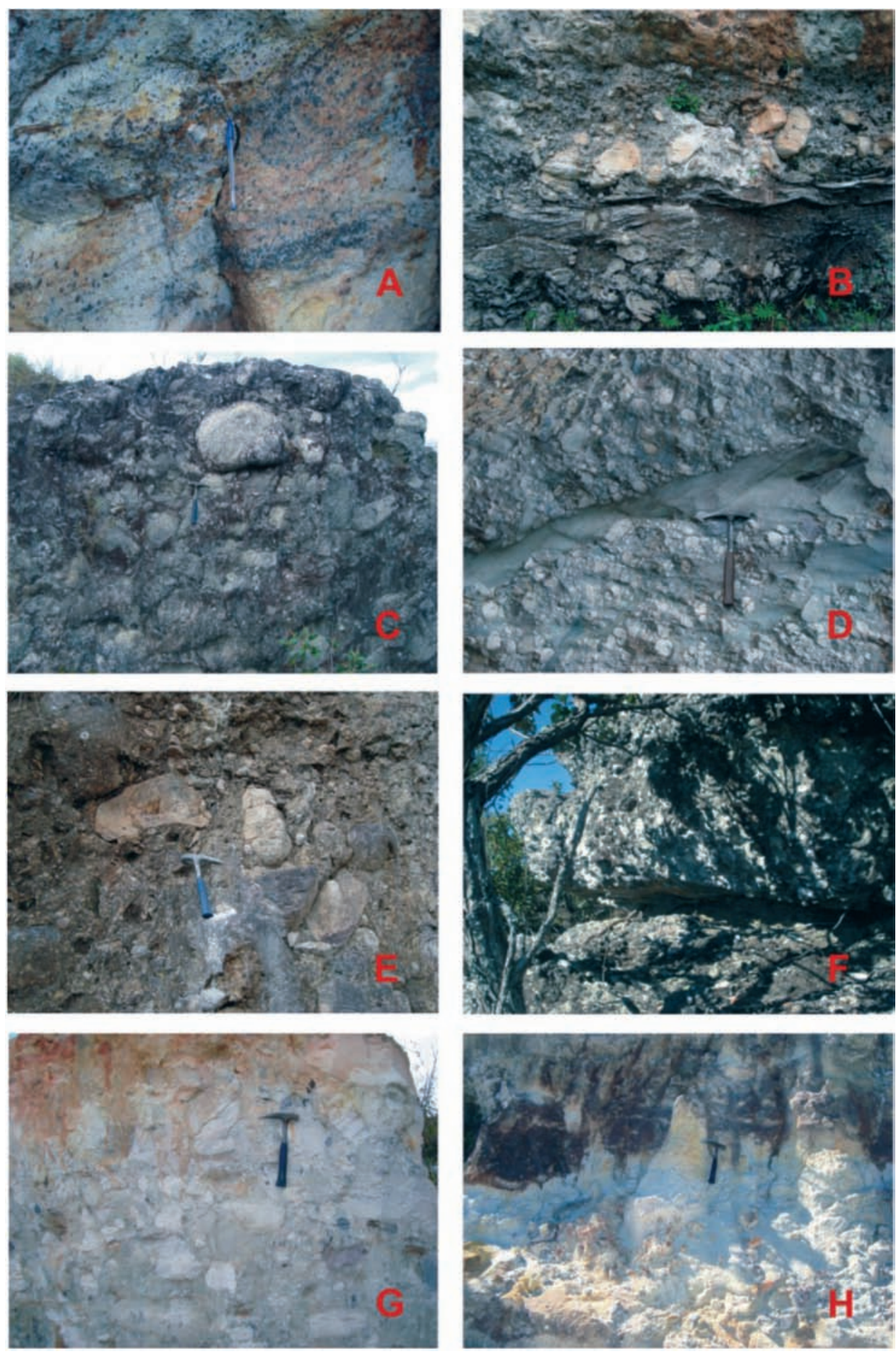

la, ou brancos maciços. Os conglomerados são maciços e de matriz imatura, suportados pelos clastos de quartzo subarredondados $(3-10 \mathrm{~cm})$.

Tais rochas foram interpretadas como resultantes de um sistema de le- que aluvial dominado por fluxos aquosos e de correntes (Blair \& Mcpherson, 1994; Galloway \& Hobday, 1996), em domínios distais, em relação à área fonte, sendo contemporâneas da Associação A3.

\section{Discussões sobre os sistemas deposicionais e paleogeografia}

No estudo da Formação SopaBrumadinho em Extração, baseado na distribuição espacial, faciologia e arquitetura deposicional dos depósitos, reconheceram-se associações litofaciológicas pertinentes a sistemas fluviais e de leques aluviais. A porção inferior dessa formação é composta por depósitos areníticos, com corpos de conglomerados e pelitos subordinados, que representam o registro sedimentar de um sistema fluvial entrelaçado (A1). Sobrepõem-se a esses arenitos conglomerados (arenitos e pelitos minoritários), configurando corpos alongados espessos, acomodados em canais incisos (erosivos), resultantes de processos fluviais mais enérgicos resultantes da tectônica distensiva dessa fase evoluti- 
va do rifte (A2). Os depósitos superiores configuram um amplo sistema policíclico de leques aluviais, progradante de WNW para ESE, influenciado pela mesma fase tectônica (A3 até A7). O caráter arcoseano e grauvaquiano, no sentido de Bates e Jackson (1987), é evidenciado pelo elevado percentual de fração argilosa (sericítica), de até $60 \%$, nos arenitos e matrizes areno-pelíticas dos conglomerados desses depósitos, contendo até $16 \%$ de feldspatos preservados. Esses dados estão de acordo com os aspectos reconhecidos desde Blissenbach (1954), para leques aluviais de regiões semiáridas atuais do sudoeste norte-americano, que denotam a elevada imaturidade sedimentar dos leques da região de Extração, constituindo argumento favorável à interpretação de que representem aportes aluviais, com sedimentação rápida (pequena distância

\section{Conclusões}

A evolução proposta para a porção inferior da Formação Sopa-Brumadinho em Extração, a partir de um sistema fluvial entrelaçado (A1) para fluvial inciso (A2), ocorreu, provavelmente, pela intensificação dos processos distensionais de abertura da bacia, que provocaram a descida do seu nível de base. Essa sequência foi coberta por um sistema de leques aluviais policíclicos (A3 a A7) com elevada espessura (superior a $100 \mathrm{~m}$ ) e grande quantidade de conglomerados. O modelo alluvial fan/sandflat/mudflat-playa (Hubert \& Hyde, 1982) explica as sequências de sedimentos das porções média e superior dessa formação. A Associação A2 evidencia transporte e sedimentação por pulsos episódicos (fluxos de detritos aquosos ou subaquosos coesivos) e, su-

\section{Agradecimentos}

À MINEREX Ltda, que apoiou financeiramente os trabalhos de campo e ao geólogo Kerley Andrade, pela par- de transporte), em ambiente controlado pela tectônica rúptil da época, sob clima semiárido a desértico.

Em relação ao paleorelevo, a distribuição espacial e paleocorrentes dos depósitos fluviais permitem definir orientações N-S (Serrinha), NE-SW (Boa Vista) e E-W (Cavalo Morto), com base na disposição de sua maior extensão longitudinal. A partir desse arcabouço, sugere-se que os conglomerados basais, na Serrinha, constituam o registro de uma drenagem axial N-S, convergente para sul em direção a uma paleodepressão, que, possivelmente, se associava a uma falha de transferência (onde agora se encaixa o ribeirão do Inferno) e que, por sua vez, recebia as drenagens secundárias registradas nos depósitos de Boa Vista e Cavalo Morto. O sentido das paleocorrentes do sistema fluvial inciso

bordinadamente, por fluxos de corrente em regime não perene, aspectos que indicam um paleoclima semiárido ou árido.

Acredita-se que o sistema de leques aluviais tenha se edificado em pelo menos três ciclos sucessivos de expansão, dominados por: (i) fluxos de corrente e de detritos aquosos, com desenvolvimento de canais entrelaçados em suas porções medianas a distais (A3 e A7), em sua fase inicial; (ii) fluxos em lençol de grande abrangência (A5); e (iii) fluxos de detritos, predominantemente não aquosos, (A4 e A6), em sua fase final. A interação do sistema fluvial com o sistema de leques teria resultado, ao longo dos diferentes ciclos tectonocontrolados, no amplo assoreamento do primeiro, postulando-se que as fases iniciais do leque pode ser inferido pelo imbricamento dos clastos na Boa Vista, para SW, em associação a leitos arenosos estratificados progradantes na mesma direção, bem como pela hierarquização das paleodrenagens segundo as estruturas do rifte a nível regional. Provavelmente, o sistema de drenagens, à época dessa sedimentação, era controlado pelas estruturas: as de primeira ordem falhas axiais (N-S) e as de segunda ordem, falhas de transferência, tranversais. Nos leques aluviais, a distribuição espacial dos depósitos, progressivamente mais finos para ESSE, atesta a conformação principal do sistema, a partir de uma fonte a WNW. Um leque subsidiário, a partir de WSW, parece ter, também, se desenvolvido, amalgamando-se ao primeiro, conforme sugerido pela distribuição areal dos depósitos (Figura 2).

tenham sido diretamente supridas, com base nas características dos sedimentos e aspectos paleogeográficos, pelo sistema fluvial, através do transbordamento dos canais incisos.

Em termos históricos, a maioria das atividades de lavra foi desenvolvida sobre os conglomerados fluviais, ora atribuídos à Associação A2. Tais serviços levaram ao quase esgotamento desses depósitos na região. Como os conglomerados da Associação A3 foram interpretados como originados a partir dos mesmos fluxos de sedimentos que geraram os depósitos de A2, e esses ainda apresentam razoáveis extensões de afloramentos, conclui-se que, provavelmente, sejam ainda detentores de significativas reservas diamantíferas.

\section{Referências bibliográficas}

ALMEIDA ABREU, P. A., MUNHOZ, D. T. V. Reconstituição paleogeográfica e estudo dos minerais pesados como indicativos de áreas fontes primárias dos diamantes da Serra do Espinhaço, Minas Gerais. In: SIMPÓSIO DE GEOLOGIA DE MINAS GERAIS, 3. Atas... Belo Horizonte: SBG-MG, 1983, p.219-234.

ALVARENGA, C. J. S. Comportamento estratigráfico da Formação Sopa-Brumadinho no distrito diamantífero de Extração (Diamantina-MG). In: CONGRESSO BRASILEIRO DE GEOLOGIA, 32. Anais... Salvador: SBG, 1982, v.1, p.168-176.

BATES, R. L., JACKSON, J. A. J. Glossary of Geology. Washington: American Geological Institute, 1987. 805p. 
BLAIR, T. C., MCPHERSON, J.G. Alluvial fans and their natural distinction from rivers based on morphology, hydraulic processes, sedimentary processes and fácies assemblages. Journal of Sedimentary Research, v. A64, p. 50-489, 1994.

BLISSENBACH, E. Geology of alluvial fans in semi-arid regions. Geological Society of America Bulletin, v. 65, p. 175-190, 1954.

BULL, W. B. The alluvial fan environment. Progress in Physical Geography, v. 1, p.222-270, 1977.

DOSSIN, I. A. et alii. Compartimentação estratigráfica do Supergrupo Espinhaço em Minas Gerais: os grupos Diamantina e Conselheiro Mata. Revista Brasileira de Geociências, v. 20, p.178-186, 1990.

DUSSIN, I.A., DUSSIN, T.M. Supergrupo EspinhaçO: modelo de evolução geodinâmica. Geonomos, v. 1, p. 19-26, 1995.

ERIKSSON, P. G. et alii. Patterns of sedimentation in the Precambrian. Sedimentary Geology, v. 176, p. 17-42, 2005.

GALLOWAY, W. E., HOBDAY, D. K. Terrigenous clastic depositional systems. Berlin: Springer, 1996, 489p.

FOGAÇA, A. C. C. Geologia da Folha Diamantina. Belo Horizonte: Projeto Espinhaço, IGC-UFMG/COMIG, 1996. 1 mapa.

HARALYI, N.L.E., SVISERO, D.P. Geologia e análise estatística do diamante da Mina da Boa Vista, Diamantina, MG. In: CONGRESSO BRASILEIRO DE GEOLOGIA, 34. Anais... Goiânia: SBG, 1986, v.5, p.2297-2311.

HUBERT, J. F., HYDE, M. G. Sheet-flow deposits of graded beds and sandstone on an alluvial sandflat-playa system, Triassic Blomidon red beds, Nova Scotia. Sedimentology, v. 29, p. 457-474, 1982.

MARTINS-NETO, M. A. O Supergrupo Espinhaço em Minas Gerais: registro de uma bacia rifte-sag do Paleo/Mesoproterozóico. Revista Brasileira de Geociências, v. 28, p. 151-168, 1998.

MIALL, A. D. Lithofacies types and vertical profile models on braided river deposits: a summary. In: MILL, A. D. (ed.), Fluvial Sedimentology. Calgary: Canadian Society of Petroleum Geologists, Mem. 5, 1978, p. 597-604.

MIALL, A. D. The Geology of Fluvial Deposits. Berlin: Springer-Verlag, 1996. 582p.

ROSIÈRE, C.A. et alii. Análise cinemática mesoscópica dos cavalgamentos do Cinturão Espinhaço na região de Diamantina, MG. Revista Brasileira de Geociências, v.24, p. 97-103, 1994.

SCHÖLL, W. U., FOGAÇA, A. C. C. Estratigrafia da Serra do Espinhaço em Diamantina (MG). In: SIMPÓSIO DE GEOLOGIA DE MINAS GERAIS, 1. Atas... Diamantina: SBG-MG, 1979, p.55-73.

Artigo recebido em 17 de fevereiro de 2011. Aprovado em 13 de setembro de 2012. 